\title{
Apuntes sobre la polémica institucionalista-marxista en torno a la cuestión sobre la mediación histórica del Estado
}

José ERNeSTO MonToYA Licenciado en Economia, Universidad Centroamericana "José Simeón Cañas Maestro en Economía Politica, Universidad Nacional Autónoma de México, UNAM

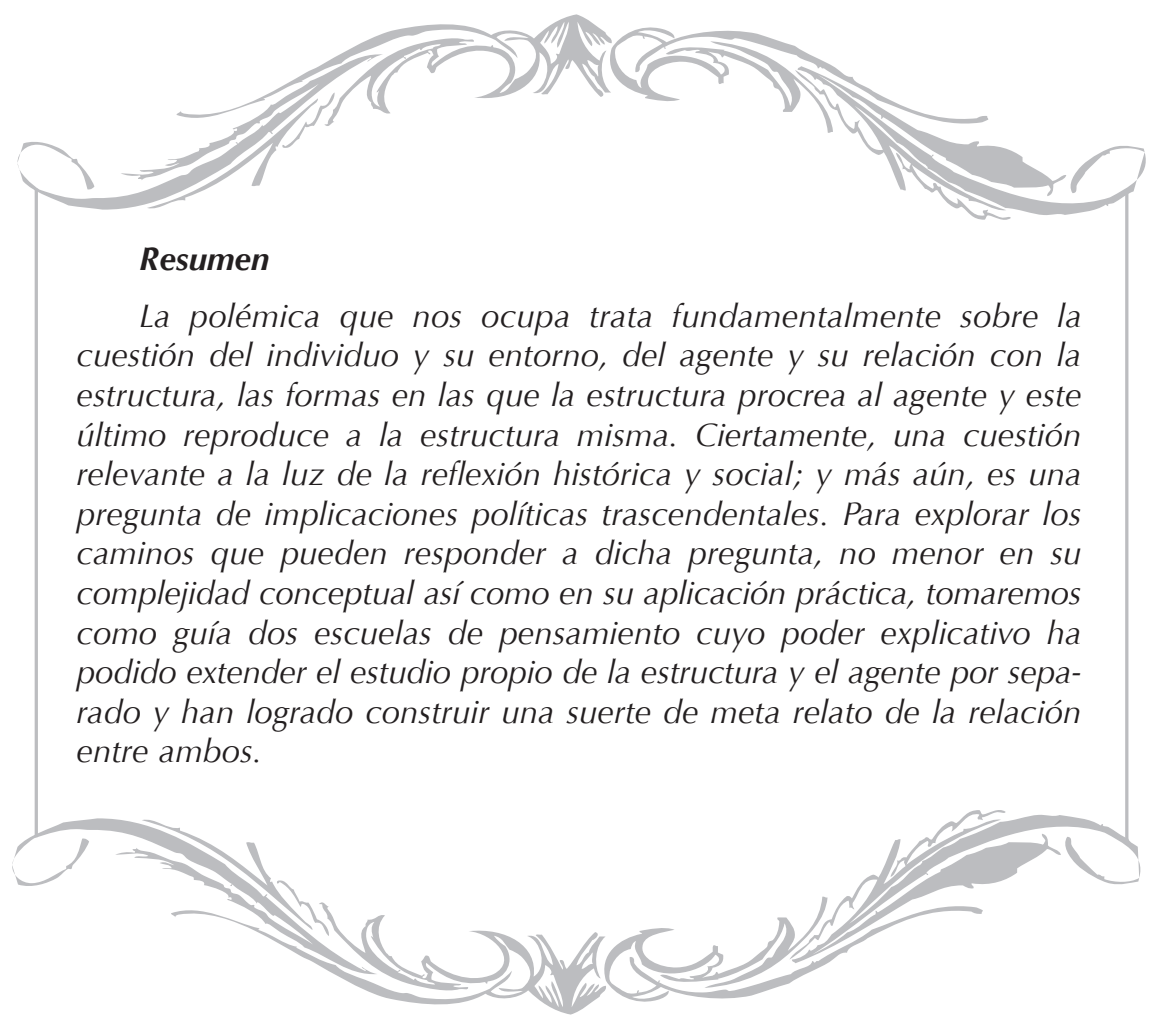




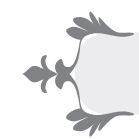

\section{La economía institucionalista original} y la nueva economía institucional

El institucionalismo es actualmente uno de los cuerpos de pensamiento -que desde la ciencia económica es considerado de vanguardia- que hacen del estudio de las relaciones del individuo y la estructura social el centro de su desarrollo teórico. No obstante, el punto central del estudio institucionalista, dicha escuela de pensamiento ha estado lejos de constituir un pensamiento unificado, y por el contrario han sido diversas líneas de investigación las que han marcado su desenvolvimiento como un marco analítico dentro de las ciencias sociales. $Y$ es precisamente en este sentido que debemos detenernos a desarrollar brevemente dos de las posturas más representativas dentro del institucionalismo -la Ilamada Economía Institucional Original (EIO) y la Nueva Economía Institucional (NEI)- para delimitar los elementos que las distinguen la una de la otra y aquellos puntos en los que hay una franca polémica.

El institucionalismo y su relación con la economía han tenido una larga trayectoria y un momento de concepción teórica lejos de ser reciente. Algunos autores como Geoffrey Hodgson (1946) rastrean el inicio del llamado "institucionalismo original" o Economía Institucional Original (EIO) hacia mediados del siglo XIX con los desarrollos de Thorstein Veblen (1857-1929), autor que con su pensamiento precursor construyó lo más cercano a un marco sistemático para la teoría institucionalista. Gran parte del pensamiento de la EIO se enmarca en el estudio de la institución y organización, para pasar posteriormente al estudio de cómo se construye la vinculación entre el individuo y la estructura que lo contiene.

De las contribuciones de Veblen al pensamiento institucionalista, se pueden mencionar: 1) el enmarcar a las instituciones y a los individuos como unidades sociales de evolución y de análisis; 2) apuntar hacia las explicaciones causales de tanto la capacidad de agencia individual como de los fenómenos sociales, consistentes con las ciencias naturales y sociales; 3) la noción de que la conducta racional surge de la habituación, por lo que reconoce la importancia del hábito por sobre el pensamiento racional; 4) el escape de los tres reduccionismos del colectivismo metodológico, el individualismo metodológico y el reduccionismo biológico; 5) el ubicar el conocimiento y el aprendizaje en el centro de la evolución económica y tecnológica; y 6) rechazar cualquier rastro de una visión teleológica del desarrollo histórico (Hodgson, 2001; 140). 
Respecto de la relación estructura individuo, Veblen dedicó mucho tiempo a estudiar el cómo y por qué sucedía esta relación, y para ello consideró que los seres humanos operaban en base a dos fuerzas, esto es, los hábitos y los instintos. Por un lado, identificó que el instinto es la parte humana, moldeada a través de años de evolución que no depende de la interacción social, que está dada por cambio y selección natural; los hábitos son, en cambio, el resultado de una evolución distinta, una evolución social -darwinismo social- y fabricada en el seno de las interacciones sociales. Veblen consideró que el hábito y la propensión natural, y no el pensamiento calculador o los intereses materiales, eran los elementos fundamentales en la motivación central de los seres humanos (Ibídem).

De este modo, Veblen estableció que la relación individuoestructura estaba sustentada sobre las bases naturales del ser humano, pero también sobre el proceso de adecuación y adaptación social de los hábitos mediante la forma de las instituciones. La relación del individuo y la estructura era una de mutua correlación, pero sobre este aspecto central. Si bien sus contemporáneos sí pudieron establecer una relación de mutua correlación entre la estructura y el individuo, Veblen lograría establecer un modo de interrelación más complejo y apegado a su concepto evolucionista de la historia y la economía; tanto la capacidad de agencia, como la estructura social, eran partes y resultado de este proceso evolutivo.

En la tradición de los institucionalistas originales -de Veblen y Commons- se le adjudica a las instituciones el rol de ser un tipo especial de la estructura social, formado a partir de la constitución histórica del hábito y la costumbre; la regla surge como objetivación del hábito bajo una forma codificable y materialmente reconocible. Será de esta forma que Hodgson (Ibídem; 29) asumirá que la estructura existente de la regla ofrece incentivos y restricciones para las acciones realizadas por los individuos, y en este sentido, "... los hábitos son el material que conforma las instituciones, $y$ les ofrece poder $y$ autoridad normativa con una mayor durabilidad" (Ibídem). Dada la definición de institución que asume Hodgson proveniente de la $\mathrm{EIO}$, la dimensión social holística adquiere un lugar preponderante en su concepción de la misma, porque el hábito no es material genético específicamente, sino material adaptable de la evolución social y por tanto -aunque inherente a la naturaleza social de los individuos- se entiende que es en la interacción humana que surge y se retroalimenta.

Dichos señalamientos que Hodgson considera actuales están en relación al abordaje que desde el individualismo metodológico se 
basa la economía neoclásica para referirse al individuo y la conformación de la estructura social. De esta forma, Hodgson establece el puente de una moderna polémica entre los economistas adherentes al marco de la EIO y los que se circunscriben a la NEl; en especial, es de interés sustancial para el autor el tratamiento que Douglass North hace de las organizaciones para estructurar el marco analítico de esta variante de la NEI. Nuestro interés en clasificar a North dentro del institucionalismo deviene del tema que nos ocupa, en tanto el estudiar la relación estructuraagente y la configuración del Estado -como organización suprema- en el devenir del desarrollo ha sido el tema central en las investigaciones de este autor. ${ }^{1}$

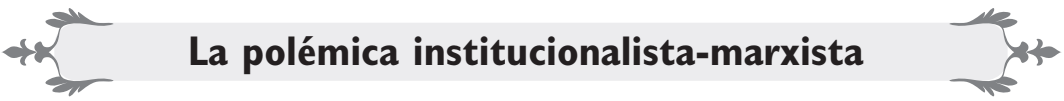

En primer lugar, sería apropiado mencionar, como primer autor relevante de la polémica, al precursor del institucionalismo original-moderno, este es, Thorstein Veblen. Recuperado en Hodgson (2001), el autor cita lo que, a su juicio, son algunos de los puntos de crítica más importantes desde el pensamiento institucionalista al marxismo; en este respecto, argumenta que Veblen "rechazó la proposición de que el individuo es exclusivamente un ser social, que cuenta en el proceso solamente como un medio para transmitir y servir de expresión de los cambios y leyes sociales" (Hodgson, 2001; 141). En esta perspectiva, y como el propio Hodgson complementaría posteriormente, el marxismo fallaría en su explicación de la relación agente-estructura al subestimar la presencia de los individuos en su propio rol frente a la estructura socio-económica. Los individuos, bajo esta visión, están relegados a ser materializaciones de determi nadas condiciones y estructuras económicas; aquí encontramos las primeras menciones al concepto de "colectivismo metodológico", posteriormente retomado por Hodgson (Hodgson, 2001 y 2004).

En segundo lugar, menciona Hodgson, Veblen criticó duramente la interpretación materialista de la historia de Marx; en su visión, el marco histórico marxista no daba cuenta de "la fuerza operativa" que trabaja en el proceso histórico de cambio. Para Veblen, dirá Hodgson, en la explicación histórica de los procesos tienen mucha relevancia los procesos causales acumulativos. De igual modo, criticó lo que para él era una visión "teleológica" de la historia en Marx, puesto que en el marco histórico vebleniano no hay un sendero predeterminado o una fuerza que conduzca al equilibrio. Por el contrario, para Veblen, la historia es influenciada por el pasado y por procesos de causación acumulativa, de tal forma que 
múltiples futuros son posibles; destinos históricos interminables, diversos e imperfectos, sea dicho de paso.

En la concepción de Veblen, Marx omitiría este paso central, pues, en su concepción del marxismo, no existía ninguna mención acerca de la forma particular en que el individuo era constructor de su propia historia, y no, como Veblen observaba en el marxismo, no pasara de ser el producto pasivo de determinadas relaciones materiales de producción. En el marxismo no existía una respuesta satisfactoria a esta pregunta, o duda, más bien, solo había confusión en los escritos de Marx (Hodgson, 2004). En esta línea, Hodgson, sucesor de Veblen, también criticó la falta de una teoría micro en el marxismo, que si bien no es fatal para el núcleo central de estudio de la teoría, sí lo sería para comprender los intereses individuales de los sujetos de la historia del capitalismo. Veblen argumentó que "la simple posición de clase de un individuo como un obrero asalariado o un capitalista nos dice poco acerca de las concepciones específicas o los hábitos de pensamiento, y, por tanto, las acciones más probables de los individuos involucrados" (Hodgson, 2001).

Hodgson cita pasajes y el prefacio de una de las obras más célebres de Marx, esto es, la Contribución a la Crítica de la Economía Política (1859). De esta obra, Hodgson cuestiona, entre algunos pasajes, el hecho de que Marx obvia la importancia que tiene el individuo dentro de las relaciones de fuerza que estructuran la sociedad, siendo estas dominadas por una estructura económica sobre la cual se sobrepone la superestructura legal y política.

En la producción social de su existencia, los hombres inevitablemente entran en relaciones definitivas, que son independientes de su voluntad... La totalidad de estas relaciones de producción constituyen la estructura económica de la sociedad, la fundación real, sobre la cual se monta la superestructura legal y política y la cual corresponde a las formas definitivas de la conciencia social" (Marx, 1971; 20, citado en Hodgson, 2004; 13).

De este modo, Hodgson argumenta que la falla del marxismo constituye exactamente el mismo problema de la neoclá- sica, esto es, el individualismo metodológico, pero invertido en el colectivismo metodológico: 
... En lugar de pretender comprender la realidad social simplemente en términos de las voluntades y las personalidades de los individuos involucrados, su concepto de la estructura hace referencia a los poderosos intereses, incentivos y las instituciones que podrían constreñir o moldear la agencia humana" (Hodgson, 2001; ibídem).

De igual forma que Veblen, Hodgson argumenta que en estas composiciones teóricas circunscritas al marco del colectivismo metodológico, el determinismo de las estructuras no solo existe como un ente explicativo de la sociedad, sino que existen con una dinámica y una lógica interna que tiende, sin más, a una suerte de explicación teleológica de la historia; esta teleología arrastra, supuestamente, también a los individuos que componen la estructura. Hodgson al igual que Veblen acusan al marxismo de crear un marco explicativo falto de una teoría adecuada que explicara la importancia que tiene el individuo, y las formas en que este individuo logra no solo relacionarse con la estructura que lo contiene, sino, asimismo, afectarla y transformarla. En la visión de Hodgson, el método marxista para explicar el funcionamiento de la estructura económica peca de asimilar dentro de ella las voluntades de los sujetos sociales activos, Ilámese capitalistas y asalariados, siendo estos simplemente expresiones de las relaciones materiales de una estructura social. (Ibídem) En este sentido, Hodgson presenta una serie de pasajes, tomados directamente de la obra "madura" de Marx, como prueba de sus señalamientos.

La función cumplida por el capitalista no es más que la función del capital... ejecutada consciente y voluntariamente. El capitalista funciona solo como personificación del capital, capital como persona, solo como el obrero no es más que el trabajo personificado (Marx, 1976; 986, citado en Hodgson, 2004; 24).

Según Ordóñez (2012; 164), la respuesta del marxismo a la crítica institucionalista descansa en dos aspectos importantes: el nivel de respuestas que se desprenden del marxismo original, desarrollado por el propio Marx; y un nivel mas elaborado y concreto, que se desprende del desarrollo del marxismo llevado a cabo por Gramsci. Según Ordónez, el plan general de investigación de Marx inicialmente incluye un aspecto puramente estructural, donde los agentes sociales son meramente personificaciones del capital, del 
trabajo asalariado y en suma de las relaciones sociales de producción. Por otro lado, existe disperso a lo largo de su obra un desarrollo de la superestructura en la que los agentes sociales son seres dotados de voluntad y conciencia a parte de las condiciones objetivas que les atan a la estructura. Es en este sentido, y la aparente contradicción que surge entre el uso de uno y otro momento de desarrollo teórico, que es posible identificar una limitante en el planteamiento de Marx basado en su falta de mediaciones teóricas entre uno y otro momento; por ello, dirá Ordónez (166), en el conjunto de la obra de Marx existe una solución implícita a la dicotomía entre agente y estructura.

La concepción de Marx frente a los agentes sociales fue una fundada sobre la noción de lucha de clases, pero este autor comprendió la conciencia de estos sujetos tanto desde la clase, como en un ámbito más amplio no confinada a esta. En la concepción marxista de la clase, la capacidad del individuo de razonar y de crearse sus propios conceptos a lo largo de la historia le otorga la posibilidad de reconstruir, mediante la praxis, una conciencia para sí en oposición al orden establecido del Estado, así como es capaz de crear un mundo de constructos culturales e ideológicos dentro de la propia clase, es decir, desde la conciencia en sí y en el marco definido por el Estado.

Es evidente que Marx no teorizó el problema de la estructura y el agente de una forma concreta que le permitiese a sus detractores entrever las sutilezas del método cognitivo de elevarse de lo concreto a la abstracto; fue precisamente este paso, el concretar la relación abstracta de la estructura y superestructura, el que daría la base del desarrollo teórico gramsciano, que permitió entender al capitalismo en su segunda historicidad: entendido como sucesión de fases históricas de desarrollo, es decir, como unidades (históricas) cambiantes entre economía, política, ideología, cultura e instituciones, que constituyen fases históricas de desarrollo en el seno del modo de producción (Ordóñez, 2012b).

\section{La visión neoclásica de las instituciones: Douglass North}

La relación estructura-agente en North, a diferencia del resto de institucionalistas, se centra en el estudio de la institución y la organización como entidades separadas y articuladas con los individuos; si bien lo anterior es especialmente evidente en la polémica NorthHodgson, es claro que el vehículo que explica la relación agenteestructura es la misma en North que para los demás institucionalistas. ${ }^{2}$ Si bien es cierto que la propia estructura explicativa de North 
ha ido cambiando en el tiempo -y reconociendo que los puntos de partida entre institucionalistas originales y neo-institucionalistas podrían ser en algunos aspectos irreconciliables-, este autor ha transitado hacia una visión sistémica e histórica de la estructura económica e institucional; cambios en sus últimas obras respecto de las primeras le llevan a cuestionar los fundamentos neoclásicos de partida, pero sin abandonarlos a priori. Lo anterior implica, obviamente, también ciertas modificaciones en cómo este autor reconoce organizaciones tan importantes como el Estado y su vinculación con el resto de organizaciones sociales.

Pero para los efectos que nos ocupa, ciertamente consideramos que North (1993 y North et al, 2009) contiene los elementos de análisis que nos interesan, en tanto es dicho autor quién elabora considerablemente la categoría del Estado y su determinación en el desarrollo histórico. Para este autor, un interés importante que aparecerá continuamente en sus obras será que para comprender los procesos económicos hay que poner atención al entendimiento de la historia y el legado cultural de la humanidad. En North, el legado cultural contiene un conjunto de instituciones y creencias que han perdurado a través de los siglos y que han moldeado el rumbo de los países y personas mediante un proceso de causación acumulativa; en consecuencia, hay una limitada capacidad de cambiarlo. La conformación adaptativa de estos conjuntos de instituciones y creencias puede tener efectos positivos o negativos en los procesos de desarrollo económico de las estructuras sociales.

Las definiciones básicas de North en torno a la institución es la de un conjunto de reglas y conceptos que rigen la forma en que se despliega una determinada interacción social colectiva (North, 1990). Así, por ejemplo, entran en la visión de instituciones de North las convenciones difundidas y generalmente aceptadas de cómo conducir y la reglamentación de tránsito respectiva. Es así como dentro del concepto "institución" se establecen conceptos claramente codificados y resaltados como normas y leyes, pero también radican acepciones informales de cómo el mundo debe funcionar. ${ }^{3}$ En contraste a la institución, dirá North, la organización se define como un grupo de individuos dirigido hacia un objetivo común, y este puede ser cohesionado por aspectos internos al grupo con los que se identifican los integrantes, o bien la imposición contractual de terceros.

En principio, y para los propósitos de North (1993), el Estado sería definido como una organización de organizaciones con la 
capacidad de incluir y excluir a grupos de la sociedad mediante la imposición particular de determinados términos de distribución inicial de los recursos de una sociedad. North define al Estado de la siguiente forma: "Un Estado es una organización con ventaja comparativa en la violencia, que se extiende sobre un área geográfica cuyos límites vienen determinados por el poder de recaudar impuestos de sus habitantes" (Ibídem; 36).

El Estado básico de North concibe a un gobernante que busca maximizar su renta mediante la organización de ciertos derechos de propiedad que abren la oportunidad de riqueza a individuos y grupos seleccionados que le son de interés estratégico. El gobernante maximizador de la utilidad o de la riqueza tiene tres características esenciales: en principio, al tener una ventaja comparativa en la violencia, el Estado intercambia un grupo de servicios relativos a la protección y justicia a cambio de rentas provenientes de los grupos de la sociedad civil. En segundo lugar, el gobernante intenta actuar como un monopolista discriminador para maximizar su renta, separando cada grupo de gobernados e ideando derechos de propiedad para cada uno de ellos. Tercero, el Estado está limitado por el coste de oportunidad de sus gobernados, ya que siempre existen rivales potenciales para ofrecer la misma clase de servicios (Ibídem; 38 y 39).
Uno de los aspectos más importantes de la concepción de Estado en North es el hecho de que sobre su capacidad extraordinario-coercitiva se trata acá de una organización encargada en determinar las reglas de juego. A su vez, las reglas del juego especifican los términos fundamentales de la competencia y la cooperación en la sociedad, mismas que proporcionarán una estructura de derechos de propiedad para maximizar las rentas correspondientes al gobernante. Los derechos de propiedad representan esencialmente los derechos de exclusión por un lado y de inclusión por el otro; la clave del desarrollo radica en qué términos se plantea la articulación de dichos derechos para involucrar a la mayor parte de la sociedad dentro del proceso de creación riqueza, o bien, para excluirla.

Esta forma de conformación institucional es desarrollada posteriormente con más detalle en North et al (2009) y la discusión que emerge alrededor de la lógica del Estado natural, ${ }^{4}$ el Orden de Acceso Abierto y la transición que entre ellos ocurre como forma de evolución institucional para alcanzar estadios más desarrollados y las implicaciones en el ámbito económico y político. En la evolución de la historia, estos Estados "naturales" están constantemente sometidos al embate de fuerzas externas que pueden alterar la composición de la coalición dominante por medios 
violentos, en tanto la fuerza es el estabilizador máximo de dichas organizaciones sociales. El cambio de una fase a otra depende de la estructuración de un nuevo pacto, o acuerdo social, que relegue el uso de la fuerza a un fin legítimo y subalterno al sistema político imperante. ${ }^{5}$

La lógica del orden de acceso abierto se distingue del Estado natural en el sentido que la entrada a la competición política por la dirección de la coalición dominante ocurre en virtud de un complejo de normas y acuerdos de carácter formal y constitucional que ampara la participación ciudadana, la conformación de entes electorales, asociaciones políticas, etc. De esta forma, y aunado a la fuerza económica y social que puedan ejercer otros agentes de la coalición, el uso indiscriminado de la fuerza militar y policial con el fin de coaccionar a los individuos queda restringida a la competencia por el poder político en la sociedad civil.

El tránsito de un Estado natural hacia un orden de acceso abierto -que es parecido a decir el paso de una dictadura a la democracia-, presenta una dificultad teórica en sí misma, ya que el propio desarrollo del Estado natural evita la emergencia de una competición abierta por el poder político, eje central del Orden de Acceso Abierto. En consecuencia, para poder realizar dicho tránsito, North reconoce que es condición sine qua non que la coalición dominante considere en el interés de las propias élites el ampliar el intercambio impersonal dentro de la élite e institucionalizar el acceso abierto a las demás organizaciones que conforman el tejido social (Ibídem).

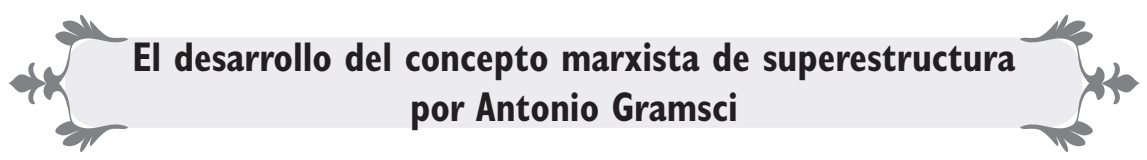

El punto de partida de Gramsci para el desarrollo del concepto de superestructura, según Ordóñez (2007 y 2012), es la necesidad de articular una explicación coherente de las fases de desarrollo del capitalismo y explicar por qué la crisis sistémica no desemboca en un proceso de revolución social y de ahí hacia el socialismo científico. De esta forma, Gramsci se ve en la necesidad de desarrollar conceptos de medicación metodológica en torno a un concepto mayor: la hegemonía. La hegemonía es entendida por Ordóñez (S/F) como la capacidad de una clase social de articular sus intereses con los de otras clases y grupos sociales en un proyecto histórico dirigido por la primera, que se realiza cuando esa clase social se vuelve dominante. 
Como lo menciona Gramsci en su reflexión sobre el "Estado gendarme-vigilante nocturno...", los elementos constitutivos del extremo coercitivo del Estado disminuyen, o que se ven disminuidos, una vez que va en ascenso y logra una consolidación plena la parte consensuada del orden establecido. Estos elementos de la "sociedad regulada" son una expresión natural de la dinámica propia de la sociedad civil. Por lo mismo, esta reflexión gramsciana del Estado nos da cuenta de una diferenciación no menor en términos del lugar que ocupa la estructura social como marco amplio de diversas subestructuras complejas; el Estado es una doble dimensión de la propia superestructura en tanto contiene los elementos de la sociedad política y aquellos pertenecientes a la sociedad civil.

La constitución de la sociedad civil, y su importante interrelación con el complejo social, es entendida por Gramsci, según Ives (2004), desde una dimensión epistémica como un tipo de conciencia colectiva de la sociedad; de esta forma, en el liderazgo y el dominio radica la esencia de la sociedad civil. Esta noción interrelacionada entre hegemonía y sociedad civil da cuenta del lugar que ocupa el Estado en la visión de Gramsci y de la forma particular en la que se articula el edificio de las superestructuras. Elementos concretos de dicho edificio integran una visión cohe- sionada del mundo y de la forma en que debería operar el mundo. Significa que son aspectos como la cultura, la filosofía, la ciencia y la política los elementos que integran el discurso hegemónico de una sociedad y, con ello, cohesionan y dan sentido histórico al sistema como un todo.

Por lo mismo, como lo escribe Ordóñez, citando a Gramsci: "El Estado ampliado tiene, entonces, las siguientes funciones generales esenciales: 1) lograr los máximos de desarrollo y expansión del grupo dirigente presentándolos como máximos de desarrollo y expansión de la sociedad, o bien realizar los objetivos históricos del grupo dirigente presentándolos como realización de los objetivos del conjunto de la sociedad; 2) adaptación de la sociedad civil a los requerimientos de la estructura económica, y, en particular, extensión de la función hegemónica desde su origen dialéctico en la estructura económica hacia las superestructuras complejas" (Gramsci, 1932-1935, C. 10, pp. 1253-1254, en Ordóñez, 2012b; 4).

Pero en la concepción marxista del Estado, posteriormente al surgimiento de la división natural del trabajo, le sigue una división social de clases que encuentra sentido en la privación como componente racional histórico de las relaciones de producción. De esta forma, en dicha concepción, la estructura 
institucional se convierte en un garante no de la propiedad privada en sí misma -como instrumento del orden-, sino como protector político-militar del orden establecido y, por tanto, de la división de clases como tal.

Al estudiar la categoría del Estado, es claro que el propósito era establecer la estructura de funcionamiento del bloque histórico capitalista y, como menciona Ordónez, plantear los medios de su superación. En este sentido, el propósito de Gramsci nunca fue ubicar al Estado en su papel de reproducción del desarrollo económico. No obstante lo anterior, en su investigación sobre el funcionamiento de la superestructura se le manifiesta la capacidad de esta de actuar a la inversa de la estructura económica en el otro lado del bloque histórico. Consecuentemente, lo político tiene una influencia clara sobre lo económico, como lo estructural tiene una influencia sobre la superestructura; y es posible entender el conjunto de la hegemonía como un determinante del despliegue de las fuerzas económicas en tanto objetivación de la forma particular de producción.
Hay que considerar, no obstante, para enmarcar la reflexión gramsciana, que en la reproducción histórica del Estado capitalista subyace la noción de lucha de clases como un elemento constitutivo del antagonismo que impregna al sistema como una totalidad coherente $y$, al mismo tiempo, contradictoria. Ello es así en razón de que en dicho antagonismo funciona la contradicción entre clases que, de igual forma, refleja toda la producción de mercancías, la recreación material y espiritual del propio sujeto y de las condiciones materiales de la sociedad en su conjunto. Lo anterior es así en virtud de que la visión de la estructura económica de Gramsci es tal, según Portelli (1980), que se manifiesta como dada y asumida dentro de la unidad de relaciones sociales y fuerzas productivas; esta concepción es congruente con la definición de sociedad civil marxista, en tanto, se trata de una noción que articula el complejo de las relaciones económicas, sociales y, con ello, la formación de clases sociales (Ibídem). Por ello, y como lo denota Ordóñez (S/F; 5),

(...) la acción estatal en la reproducción y el desarrollo económico tiene los siguientes determinantes: 1) está limitada por su contribución general a la solución del conflicto social, y, en particular, al antagonismo que enfrenta a las clases y grupos hegemónicos con la clase subalterna fundamental en el marco del bloque histórico; 2) cada época histórica tiene su propia forma de Estado y de su 
accionar en la reproducción y el desarrollo económicos, dependiendo de la solución histórica al conflicto social, y, particularmente, al antagonismo esencial de clase, que se convierten en paradigmáticos de la época; 3) los Estados nacionales entran en relación en el marco de sistemas de hegemonía de Estados; 4) la predominancia del accionar del Estado ampliado sobre el Estado en sentido restringido y viceversa, depende de la capacidad hegemónica de las clases y grupos dirigentes, correspondiendo en general a una fuerte capacidad hegemónica (predominancia de la función de dirección sobre la coerción) un accionar reducido del Estado en sentido restringido (fuerte accionar del Estado ampliado entendido básicamente en su parte de sociedad civil), y a una débil capacidad hegemónica (predominancia de la función de coerción sobre la de dirección) un accionar fuerte del Estado en sentido restringido (sociedad política), situación que puede ser una característica secular de un Estado determinado o asumir una forma coyuntural, de acuerdo con la relación de fuerzas político-sociales circunstanciales en un momento dado; y 5) este último caso (fuerte accionar del Estado en sentido restringido) supone una fuerte autonomía relativa del Estado, que abre la posibilidad de la formación de intelectuales orgánicos-políticos "lúcidos" que encabecen una estrategia de desarrollo separadamente, en términos relativos, del "sentir" general de las clases dirigentes y desde el Estado, en una situación que implica la sustitución de la clase por el Estado.

De esta forma, la separación del Estado en dos momentos, dimensiones, que otorgan sentido a la estructura del bloque histórico: el Estado en sentido restringido y el Estado en sentido amplio. El Estado en sentido restringido da cuenta del sentido gubernamentalcorporativo de una clase y/o grupo dominante que ejerce su interés mediante las diversas estructuras organizacionales que encarnan la fuerza política coercitiva del Estado.
Esta es la forma más parecida al tipo de Estado como Gobierno en funciones, identificado en la fenomenología cotidiana de la reproducción continua del Bloque Histórico. Pero en el sentido global -integralse puede entender al Estado en sentido amplio como la agregación de la sociedad política y la sociedad civil; esta agregación no es, sin más, una suma simple y/o esquemática, sino que existen mediaciones importantes en su accionar. 


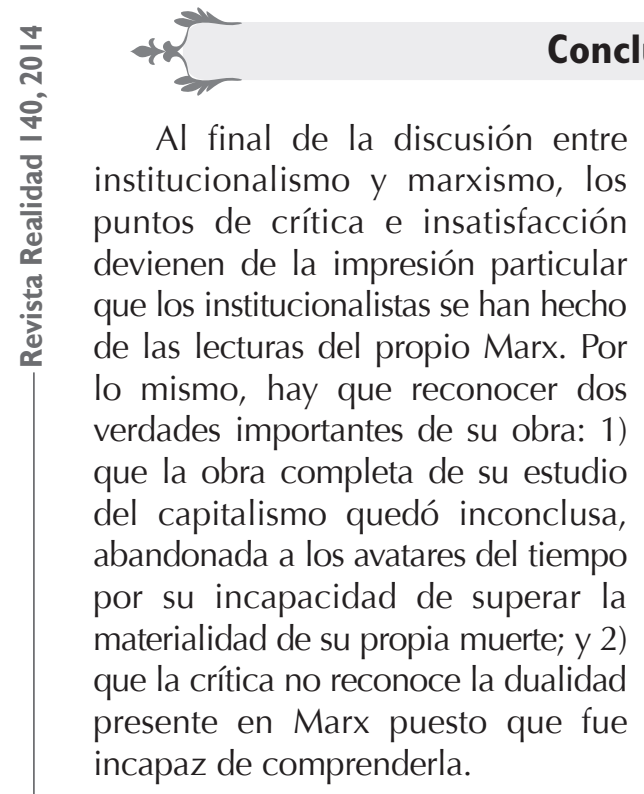

La respuesta de las críticas del institucionalismo hacia el marxismo radica en la propia repuesta del marxismo desde la lectura gramsciana al institucionalismo, en tanto responde que las fuerzas operativas del cambio social no radican en las propiedades emergentes de la sicología, sino en la política como principal praxis humana de la transformación de la propia conciencia y la conciencia de los demás. Así, la política -en su expresión materialista- se vuelve el vehículo de la humanidad para la movilización del agente y de su entorno en la consecución de un fin consciente común: la conquista y dirección del Estado como suprema aglutinación de instituciones en la superestructura.

Y el artífice de dicha construcción hegemónica es el agente, encarnado en un tipo particular de intelectual dedicado a la clase con la que se identifica. Dice Gramsci: "Todo grupo social que surge sobre la base original de una función esencial en el mundo de la producción económica, establece junto a él, orgánicamente uno o más tipos de intelectuales que le dan homogeneidad no solo en el campo económico, sino también en el social y político". Y continua: "La relación entre los intelectuales y la esfera de la producción no es inmediata, como sucede con los grupos sociales fundamentales, (ya que siendo una categoría social definida no es ella una clase social en sí misma y separada del resto) por lo que es "mediata" y en diferente escala, en toda la trama social, en el conjunto de la superestructura de la que, precisamente, los intelectuales son funcionarios". Se podría estimar lo "orgánico" de las distintas capas de intelectuales, su mayor o menor conexión con un grupo social básico. (Gramsci, 1967).

Sea como fuere, la clave de la transformación social recae en la capacidad hegemónica que un individuo o grupo de individuos proyecte desde una clase al conjunto de la sociedad. La hegemonía, pues, la hemos entendido en esta discusión como "la capacidad de una clase social de articular sus intereses con los de otras clases y grupos sociales en un proyecto 
histórico dirigido por ella que se realiza cuando esa clase social se vuelve dominante, es decir, es capaz de crear una conciencia para sí que logra ser compartida por el resto de la sociedad mediante un consenso más o menos estable" (Ordóñez, S/F).

Por otra parte, el aspecto que nos denota el mayor grado de atención en el estudio de las instituciones respecto del proceso social es el de la actuación de los determinantes hegemónicos institucionales en la configuración de una vía de desarrollo que pudiese ser considerada exitosa a la luz de su integración con el despliegue de las fuerzas productivas de una sociedad. Dicho proceso de articulación es fundamentalmente un problema al nivel de la relación estructura-agente, cuya solución es lograda mediante la dirección de las clases y grupos dominantes frente a los grupos y clases subordinadas, donde el Estado es la mediación histórica para la consecución de acuerdos sobre el rumbo de la sociedad.

\section{Bibliografía}

os Coase, R. H. 1937, "The Nature of the Firm", Economica Volumen 4, Issue 16, 386-405, noviembre.

os Hodgson, Geoffrey M. 2001, How Economics Forgot History: The Problem of Historical Specificity in Social Science (Londres y Nueva York: Routledge).

os Hodgson, Geoffrey M. 2004, The Evolution of Institutional Economics: Agency, Structure and Darwinism in American Institutionalism (Londres y Nueva York: Routledge).

os Ives, Peter 2004, Language and Hegemony in Gramsci (Londres: Pluto Press).

os North, Douglass C. 1993, Instituciones, cambio institucional y desempeño económico (México D.F: Fondo de Cultura Económica).

os North, Douglass C., Wallis, J. y Weingast B. 2009, Violence and Social Orders: A Conceptual Framework for Interpreting Recorded Human History (Cambridge: Cambridge University Press).

os Ordóñez, Sergio (S/F), Determinantes de la acción del estado en la reproducción y el desarrollo económicos en la actualidad: una visión desde los países en desarrollo (versión preliminar). PROGLOCODE (Distrito Federal: Instituto de Investigaciones Económicas, Universidad Nacional Autónoma de México). 
os Ordóñez, Sergio 2007, "Nueva fase de desarrollo, hegemonía e instituciones: retorno al futuro en Gramsci", Economía Informa, núm. 348 septiembre-octubre 2007 pp. 26-47 (Distrito Federal: Facultad de Economía, Universidad Nacional Autónoma de México).

os Ordóñez, Sergio 2012, "Países emergentes: polémica marxismo-institucionalismo", Problemas del Desarrollo, 170 (43), julio-septiembre 2012 pp. 155-184 (Distrito Federal: Instituto de Investigaciones Económicas, Universidad Nacional Autónoma de México).

os Ordóñez, Sergio 2012b, "Determinantes de la acción del estado en la reproducción y el desarrollo económicos en la actualidad: una visión desde los países en desarrollo". Ponencia presentada en el Seminario: Economía del Conocimiento, Desarrollo y Estado, en el Instituto de Investigaciones Económicas de la UNAM, México D.F, del 07/31/2012 al 08/02/2012.

os Parada, Jairo J. 2003, "Economía Institucional Original y Nueva Economía Institucional: Semejanzas y Diferencias" Revista de Economía Institucional, vol. 5, No 8, Primer Semestre de 2003 92-116 (Bogotá: Universidad Externado de Colombia).

os Peter A. Hall and Rosemary C. R. Taylor 1996, "Political Science and the Three New Institutionalisms public lecture during the MPIFG Scientific Advisory Board", Board's meeting on May 9, 1996.

os Portelli, Hughes 1980, Gramsci y el Bloque Histórico (Distrito Federal, Siglo XXI editores).

o3 Gramsci, Antonio 1967, La formación de los intelectuales (Distrito Federal, Editorial Grijalbo) Versión español de Ángel González Vega.

\section{Notas}

1 Ronald Coase se convirtió en uno de los pioneros en la crítica del tratamiento que la teoría neoclásica hacía de las instituciones cuando en 1937 publicó un estudio seminal sobre el rol y la naturaleza de la firma. En este trabajo pivote de la NEI, Coase (1937) propuso la noción de que existían costos de transacción que determinaban el acceso al sistema de precios; de esta forma, el autor argumentó que el mainstream había marginado indebidamente el rol de toda institución a parte del mercado, puesto que el propio mercado no estaba exento de la dependencia del uso de las instituciones para su funcionamiento. La importancia de los costos de transacción para el futuro desarrollo de la NEI ha quedado patente en el desarrollo de los posteriores proyectos de investigación de grandes exponentes de dicha escuela. La noción de costos de transacción se convirtió en un elemento recurrente en el modelo teórico desarrollado por Douglass North, y ha dado origen a la llamada escuela North-Williamson, pero también a otras vertientes (Parada, 2003). 
2 Para explicar con detalle la ubicación de North, y su particularidad dentro del neo-institucionalismo, en primera instancia debemos abocarnos a la clasificación de Hall y Taylor (1996) en la que separan a estos autores en tres grandes subgrupos: los autores del institucionalismo histórico, la variante sociológica y el institucionalismo de la elección racional. De acuerdo a esta clasificación, tanto North como Williamson pertenecen al llamado "Institucionalismo de la Elección Racional" (IER). El IER, en oposición a las variantes históricas y sociológicas de la NEI, es un cuerpo más sistemático de teoría muy vinculado a los fundamentos neoclásicos; en términos generales, el marco metodológico de este neo institucionalismo se construye sobre las bases del individuo y su relación con la estructura. Para el caso, Hall y Taylor describen que los autores adherentes al IER adoptan para sus agentes racionales un conjunto particular de preferencias definidas y actúan acorde a estas de una forma sumamente estratégica y calculadora, de igual forma comprenden la concepción del poder político como una serie de dilemas de acción colectiva. En tercer lugar, esta vertiente se caracteriza por enfatizar el rol de la interacción estratégica entre agentes a la hora de estudiar los resultados políticos; el énfasis vendría dado por el individuo -o grupo de estos- y la influencia suprema que tiene sobre su acción la expectativa que tenga de los otros individuos. Las instituciones son entendidas acá como la mediación social que permite o restringe tales interacciones por medio de mecanismos de control que reducen la incertidumbre; por tanto, la institución se vuelve una función del valor que los individuos encuentran en ella.
3 Como ejemplo de esta ambivalencia conceptual, North et al (2009) cita el caso del funcionamiento del sistema electoral en las distintas sociedades: el hecho de que un país tenga elecciones no implica que exista democracia, pues la clave de la misma radica en la instauración de un orden con derechos abiertos que permita la mayor competencia política. Es decir, la forma institucionalizada de elección carece de sentido real si a la base hay una desconfianza generalizada por parte de la sociedad civil en que el resultado electoral tendrá algún impacto sobre la configuración de hacer política nacional; o bien, por el otro lado, si las clases y grupos dominantes usan el mecanismo electoral solo como un medio institucional para legitimar un uso faccioso del aparato estatal basado en la construcción de un orden social cerrado y asiduo de prácticas oligárquicas.

4 Según este mismo autor (Ibídem; 18), en el Estado natural se encuentra una forma "primordial" de poder político, expresada en la fuerza y el costo de oportunidad que implica la fragmentación de la coalición dominante; y es esas dos fuerzas lo que cohesiona a la sociedad. La coalición dominante es el mecanismo de unidad institucional que rige el rumbo del Estado natural, y en su centro yacen los llamados "especialistas" que desempeñan una función social en lo económico, lo político, lo religioso y, de sobre manera, en lo militar. El balance o equilibrio "del terror" se obtiene mediante la conformación de un pacto o creencia compartida sobre que la fragmentación de la coalición implicaría la pérdida de una renta percibida mayor a que si se mantuviera unida. O como North et al (2009; 20) lo escribe: "Los incentivos implícitos en estas organizaciones 
producen un doble equilibrio: una correspondencia entre la distribución y organización de la violencia; poder potencial y político por una parte, y la distribución y organización del poder económico por la otra".

5 En estas condiciones, el Orden de Acceso Abierto debe fundamentalmente controlar la violencia entre sus miembros, a través de: 1) la subordinación del uso de la violencia mediante la organización de la fuerza militar y policial en función del control y dirección del sistema político; 2) el sistema político debe ser constreñido mediante el uso de instituciones e incentivos que limiten el uso ilegitimo de la violencia; y 3) para que una facción o partido político permanezca en el poder debe gozar del apoyo y reconocimiento de un amplio grupo de intereses económico y sociales (Ibidem; 22). 